\title{
ACCESSIBILITY OF SLOVENIA'S MUSEUMS FOR BLIND AND VISUALLY IMPAIRED
}

\author{
Raša Urbas ${ }^{1}$ (D), Ana Kuščer ${ }^{1}$, Mexhid Ferati ${ }^{2}$ (D), Urška Stankovič Elesini ${ }^{1}$ (iD \\ ${ }^{1}$ University of Ljubljana, Faculty of Natural Sciences and Engineering, Department of Textiles, \\ Graphic Arts and Design, Chair of Information and Graphic Arts Technology, Ljubljana, Slovenia \\ ${ }^{2}$ Linnaeus university, Faculty of Technology, Department of Informatics, Kalmar, Sweden
}

\begin{abstract}
Accessibility of museums and other cultural institutions is not equal for all visitors. Since the perception of the human surroundings bases mainly on the visual experience, people with vision disabilities, either blind or visually impaired, are deprived of this kind of experience. Desiring to provide an equivalent user experience more and more institutions show the tendency of offering different variations of adjustments.

Adjustments for blind and visually impaired are usually limited to the use of existing exhibition materials for all visitors either in the form of audio guides, guides or brochures in Braille, tags in Braille, less often tactile objects, tactile maps, floor markings, larger signs or indicators, magnifying glass, and sound elements. Though it seems that numerous adjustments are being used, the reality shows that they are still rare. Besides that, these materials and adaptations usually do not fulfil the requirements of adequate museum experience therefore, the need of improving the current state is necessary.

In this paper an overview of needs and demands, which need to be fulfilled within the graphic arts and communication technologies possibilities, either for Braille, tactile or audio demands for presenting the lack of visual experience with blind and visually impaired, is presented.
\end{abstract}

Key words: adaptations, audio guide, blind and visually impaired, museums, tactile recognition, user experience

\section{INTRODUCTION}

People are multisensory living beings who are estimated to gain from $80-85 \%$ of their surrounding perception through vision (Politzer, 2008). Though it can be stated that we live in highly visual world where information is mainly visually experienced, people who cannot use all their senses are able to form a credible representation of surroundings (Kermauner, 2014). Therefore, it cannot be stated that the world structured with all senses is much more real than the one structures with one or more senses missing.

The blind and visually impaired are able to partially replace the missing sight with other senses, mainly by touch, as a contact sense, and hearing, as a distant sense (Hersh, 2008). They use the sense of touch to read Braille and other tactile recognizable elements, or to recognize certain objects. Hence, they can develop a much better hearing and recognize certain objects with the help of it. In spite of mentioned there are still numerous limitations in different user experiences. One of them is the accessibility of museums and other cultural institutions. Since they are mainly adjusted for visual, and sometimes audibly, presentations of a wide variety of exhibits, pieces, displays etc. people with vision disabilities, either blind or visually impaired, are deprived of this kind of experience. Desiring to provide an equivalent user experience more and more institutions show the tendency of offering different variations of adjustments (Levent et al, 2013a; Levent et al, 2013b).

Adjustments for blind and visually impaired are usually limited to the use of existing exhibition materials for all visitors either in the form of audio guides, guides or brochures in Braille, tags in Braille, less often tactile objects, tactile maps, floor markings, larger signs or indicators, magnifying glass, and sound elements. Though it seems that numerous adjustments are being used, the reality shows that they are still rare. Besides that, these materials and adaptations usually do not fulfil the requirements of adequate museum experience therefore, the need of improving the current state is necessary.

The use of graphic arts technologies and communication techniques enable numerous possibilities for adapting not only the exhibitions artefacts and objects, but also the written content and audio descriptions as well as some other variations (Bowe, 1993; Cullen, 2001).

Many museums have already successfully implemented the use of digital screens, multimedia visualizations on different devices, and most commonly the use of different audio guides (Othman et al, 2013). The latter, in particular, present a common way of providing additional information. Lately, audio guides are upgraded 
with different applications that can be used on smart phones, tablets or similar devices. Users can access the audio guide with their device, either by downloading the application, or by using web based one.

Museum programs for the blind and the visually impaired roughly fall into the categories of verbal description tours and touch tours. Though this can significantly improve the museum user experience of blind and visually impaired, the content is in many cases defectively and inadequately presented. Namely, due to the fact that many exhibits, pieces, displays etc. are exclusively available for viewing only the lack of basic information (precise description of the size, the shape, the source material, the color etc.) deprives the blind and the visually impaired visitor of adequate presentation (Rice et al, 2006; Hall, 2009).

Some museums offer tactile elements, either as the original historical or art works, or as replicas, some offer different models or objects that are in a way related to the visual material. All these objects are, compared to the numerous exhibits and museum pieces, still very rare. Their rarity is not solei attributed to the production costs, but the depicting and their production must also be considered. Namely, objects, presented for normally sighted, carry in their visual representation numerous information - shape, size, color, surface and in some cases inner structure, composition, etc., which are, when adapted into the tactile presentation, usually strongly limited. It is very hard, if not sometimes impossible, to present for instance the shape, color and the length of persons hair, their facial properties (e.g. color of cheeks and lips, eyes, wrinkles ...), shape and pattern of their clothes, etc. Tactile impressions are limited, therefore depriving the information of presented object. The same could be said also for the written information in Braille. Additional information in text guides and brochures.

For ensuring an adequate museum accessibility and experience proper adaptations need to be made. The aim of this research was to establish the current state of adaptations for blind and visually impaired in Slovenia and on the bases of findings to prepare an overview of possibilities and solutions, which would offer the blind and the visually impaired comparable user experience as with the normally sighted. This paper offers an overview of needs and demands which need to be fulfilled within the graphic arts and communication technologies possibilities either for Braille, tactile or audio demands for presenting the lack of visual experience with blind and visually impaired.

\section{RESEARCH METHODS}

The research was divided into three parts - preliminary, qualitative and quantitative research.

The preliminary research consisted the study of the current situation in Slovenian museums and their accessibility for the blind and visually impaired. The objective was to establish whether and in what manner are Slovenian museums adapted for this group of visitors. Furthermore, our second goal was to establish if there are any audio applications being used, and if, what are their types. In the study 73 Slovenian museums and their collections were included. We examined the museums' websites to gather the information regarding their accessibility for the blind and visually impaired. The collected information was later upgraded with telephone interviews.

The quantitative research consisted of questionnaire in which we asked the respondents for the purpose of using smart phones and their experience with different applications, usage of computer and in general about the use of information-communication technology (ICT) in their everyday life. The questionnaires of quantitative research were sent by e-mail to the group of participants and their written results (answers) were later analysed. Thirteen interviewees participated in the research ( 4 female and 9 males), among which three had low vision, while others were blind.

At the end, the qualitative research was conducted. Seven blind people participated ( 2 female and 5 males, age from 20 to 51) in personal interviews where we have used the method of contextual inquiry. A smaller number of participants is attributed to the fact that the number of blind people in Slovenia is relatively small, among which not all are using ICT devices and tools. Interviews were performed in accordance to the previously prepared questions. Afterwards, we asked the interviewees to show us some of the tasks they usually perform on their smartphones, and, also, to show us some of the applications they use. The interviewees who use applications for navigation were asked to show us how they use them in context, of course, if possible. Results of all three research parts are presented in the continuation. 


\section{RESULTS AND DISCUSSION}

\subsection{Preliminary research results}

The research has shown that there are 14 Slovenian museums that have some sort of adaptations with differing scope for the blind and the visually impaired (Figure 1).

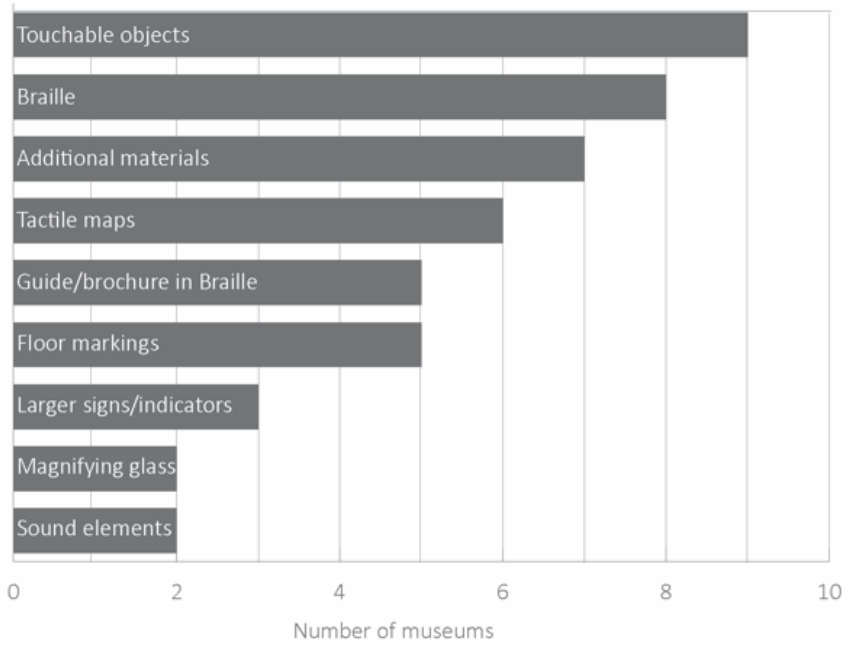

Figure 1: Accessibility of Slovenian museums for the blind and the visually impaired

Nine of those museums present diverse tactile objects (mostly as some sort of replicas). Often, there are only certain exhibition objects available as tactile objects, or only particular parts of the exhibitions. Eight museums display information in Braille (usually only labels for the presented objects and pieces), while five offer guide or brochure in Braille. Information written in Braille is very often less extensive than written in Latin. Guides and brochures for normally sighted are visually attractive and mainly image presented, while the written content is most often short and only basically informative. Due to the fact that images are not suitable for preparing this kind of material for the blind and the visually impaired, all the content needs to be in Braille. But when preparing in braille it must be considered that Braille has other demands than Latin - Braille needs to be of certain size, which is much larger than Latin and being written on Braille typewriters it is normally only one-sided. Therefore, prepared initial texts in Latin are, when rewritten in Braille, often shortened, offering this group of museum visitors less information. Research has also shown that seven Slovenian museums offer some sort of additional material (their type was not specified on the web pages), while six of them offer tactile maps, five have floor markings for easier navigation of the blind and the visually impaired, and three museums have larger signs for the visually impaired, or some type of indicators. The fact is, that majority of museums are either partially adapted for the blind and the visually impaired or present only temporary adapted exhibitions. The only fully adopted museum for the blind and the visually impaired is the Museum of post and telecommunications in Polhov Gradec, which offers tactile objects, Braille presented contents, sound elements, tactile maps and floor markings, thus enabling their blind and visually impaired visitors the possibility of independent museum visit (Figure 2).

Though there are several museums in Slovenia that offer audio guides for their visitors, only one museum in Slovenia offers an adapted audio guide for the blind and visually impaired, which offers visual descriptions of the exhibited objects. There are 16 museums in Slovenia that use the Nexto audio guide mobile application (Proxima, Slovenia) and none of the museums offer a mobile guide application that would be especially adapted for the blind and the visually impaired. Nexto application possesses no special adaptations for the blind and the visually impaired, but is somewhat accessible with VoiceOver (iOS) and Talkback (Android), and, therefore, can be used by the blind and the visually impaired visitors, as well as sighted ones. 


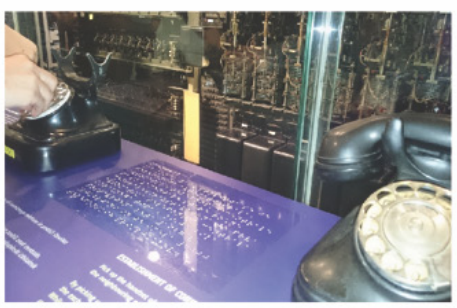

adaptations in Braille

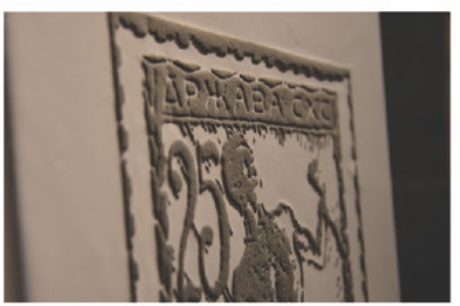

tactile image

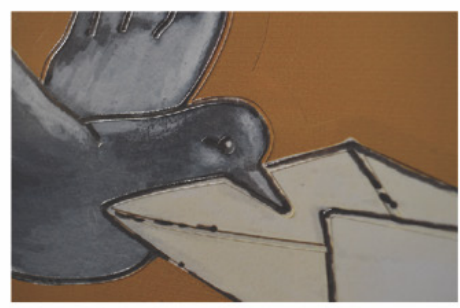

tactile adaptation of an image

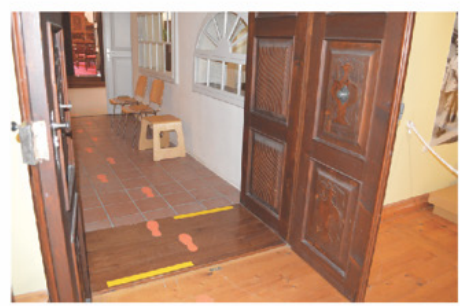

floor markings

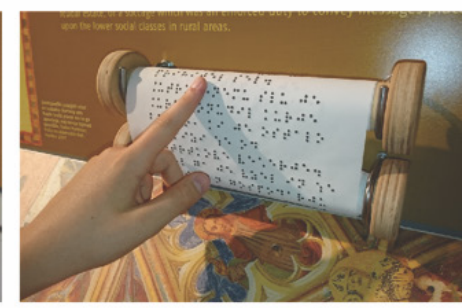

touchable replica

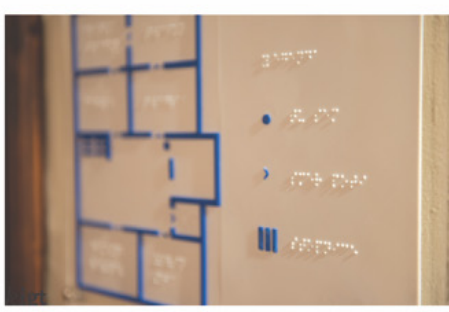

tactile map

Figure 2: Adaptations for the blind in the visually impaired in the Museum of post and telecommunications, Polhov Gradec

\subsection{Quantitative research results}

ICT technology today presents a part of everyday life. Its use is widespread among world population and it is not gender or age limited. Therefore, it is not surprising that even blind and visually impaired use smart devices and applications.

In the quantitative research, we wanted to establish in what way the blind and the visually impaired interact with mobile/smart devices, and for what purposes they use them. Research has shown that the blind and the visually impaired interviewees use their smart phones mainly for phoning $(92,3 \%)$, using different applications, and texting (84,6\%). Two thirds of respondents $(69,2 \%)$ use their phone for web browsing and navigation (Figure 3). Furthermore, the research has shown that the use of smart phone helps blind and visually impaired with their everyday activities, enabling them greater independence.

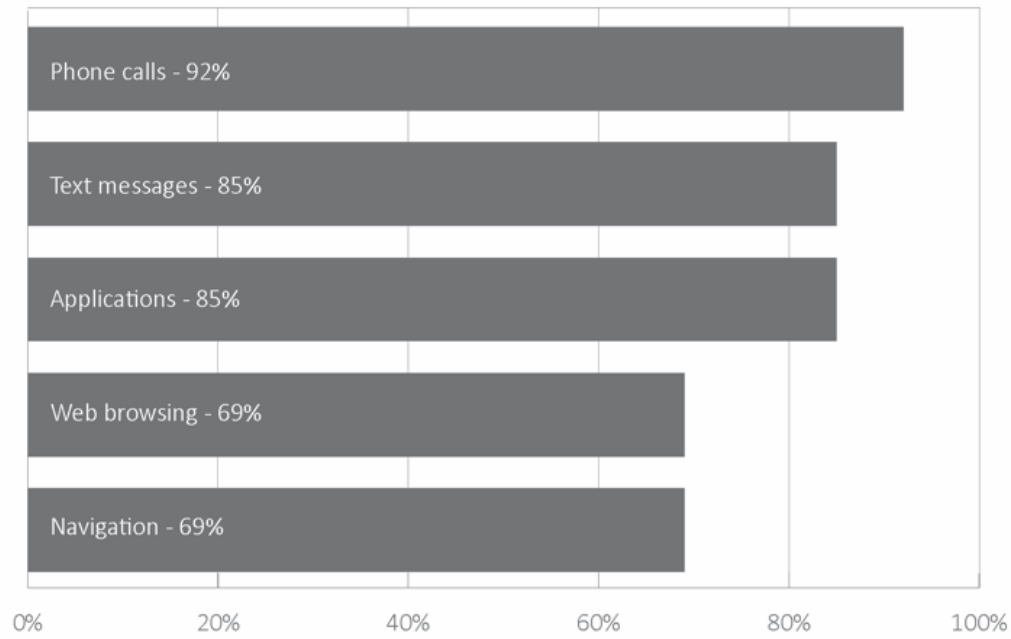

Figure 3: Usage of smart phones

We were also interested in what kind of applications and how often do they use them. Surprisingly quarter of respondents (23\%) use 9 or more applications, while other (77\%) use 6 or less. Among most frequently used applications are popular social media apps e.g. Facebook and Messenger, and at the same time navigation for blind and visually impaired applications (Moovit, Lazarillo, Navigation) and usual transportation applications (Slovenian versions - LPP Bus, Prevozi) (all 38\%). The respondents also frequently use e-mail and music apps (31\%), less often calendar, call and chat aps (Viber, Skype), health 
and sports apps, online television, Siri, weather applications and YouTube (all 15\%). They also use other applications (e.g. calculator, camera, Google, reminders etc.) though their use depends on the user. The blind and the visually impaired often rely also on applications developed intentionally for their use like Be my eyes and Tap Tapsee.

It could be concluded from the research that the blind and the visually impaired use their smart devices in the same manner as normally sighted. Therefore, the use of ICT technology presents a useful tool for presenting the surrounding world not only in everyday life but also in the museums and other cultural activities. Smart devices present not only video content but can also be used as audio descriptors.

\subsection{Qualitative research results}

For determination of requirements and needs of technical and user experience properties of applications we interviewed blind persons (7) who had different experiences about museum visits. Majority of them have already visited different museums in Slovenia and abroad, where they have used an audio guide device or an audio application as a guide while the visit. Their experience differed. Some have used audio guide devices where the users input by themselves the number assigned to a certain object while other used audio guide devices that detects near-by objects. The interviewees agree that for a positive blind and visually impaired user experience audio guide device shouldn't have too many buttons and should be easy to use. Selecting a proper number assigned to object is easy if audio guides device is user friendly, on the other hand if it is complicated blind or visually impaired visitor can have problems with its use. With automated audio guide device (usually connected to NFC tags) some function problems can occur if presented objects are positioned too close together, when movement can trigger a beginning of another description audio tape. One of the interviewees also mentioned an experience from a museum where an application detected through a camera if a certain object was near, and, therefore, provided information about the object.

Regardless to the type of audio guides, recorded descriptions should include precise visual descriptions of objects, containing information about dimensions, colours, locations etc. Sometimes, a blind person has difficulties imagining how big a certain object is if it is only described in relative terms. However, if it is presented with specific information, like measurements, or compared to another object, it is easier for them to get an idea how the object looks like (Neves, 2008; Salzhauer et al, 2003). Also, it is useful to know the precise location of a certain object in comparison to the location of the other objects. Each element needs to have a correct description in the source code with simple input fields.

Research has shown that interactions with smart devices (phones, tablets, etc.) play an important role. Simplicity of use enables good user experience regardless of their purpose. Devices for audio guides can be more user friendly to the blind and visually impaired if they enable scrolling the screen in both directions, thus enabling the selection of certain recording or element, which can be selected by double clicking. Every time the users reach a new element, a beep goes on, and, at the same time, the phone vibrates so that the users know they are located on a new element. Sliding offers users more freedom while navigating then scrolling. Good examples of this practice are Talkback and Voice over. Application needs to follow the Web Content Accessibility Guidelines (WCAG 2.0) which explain how to make web content more accessible to people with disabilities (W3C, 2018).

In applications for the blind and the visually impaired the usage of graphic elements should be limited, however, if used, they should have an appropriate name in the code. If the application offers more buttons to choose from, or other options on the screen, it doesn't present an obstacle for the user, as long as they are presented in the correct manner. The research has also shown, that setting up a web-based application presents and advantage, thus it can be used on all operating systems.

With audio guides it is important to think about the usage of head phones, which offers visitors privacy during a visit. Headphones are usually paired, but because blind get a lot of information about the world around them threw hearing, they prefer to use headphones only in one ear.

\section{CONCLUSIONS}

Research has shown that Slovenian museums offer different kind of adaptations for blind and visually impaired, though the majority bases on presenting some of the information in Braille or on exhibiting certain tactile objects. Because visual experience isn't enabled for the blind and visually impaired, for achieving adequate presentation exhibited items need to be either fully verbally or written presented. 
For firstly mentioned, museums and other institutions usually use audio guides, which are also being used for normally sighted though voice recorded apertures. However, these guides are often not properly adapted for the use of blind and visually impaired. They lack of precise object descriptions and their user commands are not suitable for this group of people. In the contextual research, we have discovered that the blind and the visually impaired use their smart phones in a similar manner as the sighted, with the only difference that the navigation works differently. Therefore, the blind and the visually impaired are able to use all applications and web pages, as long as their code is written properly, so that it can be read with a screen reader. Furthermore, a code of the application needs to be written in a form of a screen reader compliant. In such a way, it will be accessible to the blind users with either TalkBack or VoiceOver. Application needs to follow the guides of the WCAG 2.0 standard.

Secondly mentioned written materials in Braille have usually content shortened because texts in Braille take up more space than ordinary texts due to the demands and standards of Braille. Thus, information is usually more scattered and does not satisfy the curious ones.

When the museum is made accessible, it is necessary to think about the achievement of the intended goals. A new relationship with the blind and the visually impaired who decided to stop going to museums needs to be formed, and, moreover, to attract those who have felt unwelcomed before, or have never visited a museum at all (Levent et al, 2013a).

\section{REFERENCES}

[1] Bowe, F. G.: "Access to the Information Age: Fundamental Decisions in Telecommunications Policy", Policy Studies Journal 21(4), 756-74, 1993.

doi: 10.1111/j.1541-0072.1993.tb02173.x.

[2] Cullen, R.: “Addressing the digital divide", Online Information Review 25(5), 311-320, 2001. doi: 10.1108/14684520110410517.

[3] Hall, C. A.: "Web Presentation Layer Bootstrapping for Accessibility and Performance", Proceedings of the 2009 International Cross-Disciplinary Conference on Web Accessibility (W4A), (Madrid, Spain, 2009), pages 67-74. doi: https://doi.org/10.1145/1535654.1535671.

[4] Hersh, M. A., Johnson, M. A.: "Assistive Technology for Visually Impaired and Blind People", (Department of Electronics and Electrical Engineering, University of Glasgow, Glasgow, 2008), page 52. doi: 10.1007/978-1-84628-867-8.

[5] Kermauner, K.: “Avdio-haptično-virtualna Mona Lisa”, Časopis za kritiko znanosti, domišljijo in novo antropologijo 42(255), 173-181, 2014.

[6] Levent, N., Kleege, G., Pursley, J. M.: "Museum Experience and Blindness", Disability Studies Quarterly 33(3), 2013a.

[7] Levent, N., Reich, C.: "Museum Accessibility: Combining Audience Research and Stuff Training", Journal of Museum Education 38(2), 218-226, 2013b. doi: 10.1080/10598650.2013.11510772.

[8] Lievrouw L. A., Livingstone S. eds.: "Perspectives on Internet Use: Access, Involvement and Interaction", in The Handbook of New Media, (editors: Lievrouw L. A., Livingstone S., SAGE Publications Ltd., London, 2006), pages 92-113.

[9] Neves, J.: "Descriptive guides: Access to museums, cultural venues and heritage sites", in Pictures painted in words: ADLAB Audio Description guidelines, URL: http://www.adlabproject.eu/Docs/adlab\%20book/ (last request: 2018-02-24).

[10] Othman, M. K., Petrie, H., Power, C.: "Measuring the usability of a smartphone delivered museum guide", Procedia - Social and Behavioral Sciences 97, 629-637, 2013. doi: 10.1016/j.sbspro.2013.10.282.

[11] Politzer, T.: "Vision is our Dominant Sense", Brainline, URL: https://www.brainline.org/article/visionour-dominant-sense (last request: 2018-04-15).

[12] Salzhauer Axel, E., Hooper, V., Kardoulias, T., Stephenson Keyes, S., Rosenberg, F.: "ABS's Guidelines for Verbal Description", in Art Beyond Sight: A Resource Guide to Art, Creativity, and Visual Impairment (editors: Salzhauer Axel, E., Sobol Levent, N., New York: AEB and AFB Press, 2003), pages 229-237.

[13] W3C, Web Accessibility Initiative (WAI): "Web Content Accessibility Guidelines (WCAG) Overview", W3C, 2018, URL: https://www.w3.org/WAI/standards-guidelines/wcag/ (last request: 2018-09-04). 


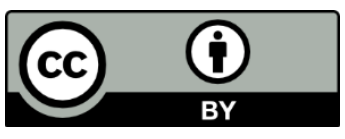

(C) 2018 Authors. Published by the University of Novi Sad, Faculty of Technical Sciences, Department of Graphic Engineering and Design. This article is an open access article distributed under the terms and conditions of the Creative Commons Attribution license 3.0 Serbia (http://creativecommons.org/licenses/by/3.0/rs/). 